\title{
Cavernomas in children with brain tumors: a late complication of radiotherapy
}

\author{
J.F. Martínez-Lage*,****; I. de la Fuente**; J. Ros de San Pedro*; J.L. Fuster***; M.A. Pérez-Espejo*,**** y \\ M.T. Herrero****
}

Servicios *Regional de Neurocirugía, **Oncología Radioterápica, ***Oncología Pediátrica. Hospital Universitario Virgen de la Arrixaca. Murcia. ****Grupo de Neurociencia Clínica y Experimental (NECEX). Facultad de Medicina de la Universidad de Murcia.

\section{Summary}

Background. Delayed complications of radiation therapy comprise cerebral atrophy, radionecrosis and induction of tumors. Recent reports indicate the possibility of the "de-novo" formation of intracranial cavernomas in patients submitted to radiation therapy to the brain.

Objectives. To report three children, two with medulloblastomas and one with a pineal germinoma, treated with radiotherapy that developed intracerebral cavernous hemangiomas some years after treatment. With this work, we aim to draw attention to this occurrence in the neurosurgical community.

Results. The patients were two girls and one boy with ages comprised between 2.5 and 7 years (mean 5.2 years). The average interval from irradiation to the appearance of cavernoma was of 5.3 years (range 5-6 years). The lesions were found during the routine neuroimaging studies performed for the follow-up of their primary neoplasms. No patient showed signs or symptoms related to the cavernomas. However, the three children will need both clinical and neuroimaging surveillance to monitor the evolution of these incidentally discovered lesions.

Conclusions. Intracranial cavernomas can occur years after cerebral radiation therapy. In spite of previous reports that show a high incidence of bleeding lesions, cavernomas may be found incidentally during the neuroimaging surveillance studies that are performed to children with brain tumors previously treated with radiotherapy. In these cases, a conservative attitude seems to be advisable, reserving surgery only for those lesions that grow or bleed.

KEY WORDS: Cavernoma. Incidentaloma. Radiation induced cavernoma. Medulloblastoma. Pineal germinoma. Adverse effects of radiation therapy.
Cavernomas en niños con tumores cerebrales: una complicación tardía de la radioterapia

\section{Resumen}

Antecedentes. Entre las complicaciones tardías de la radioterapia se encuentran la atrofia cerebral, la radionecrosis y el desarrollo de tumores radioinducidos. Se ha descrito recientemente la formación de cavernomas intracraneales en pacientes tratados con radioterapia cerebral.

Objetivo. Presentar los casos de tres niños, dos con meduloblastomas y uno con un germinoma pineal, en los que se encontraron cavernomas cerebrales años después del tratamiento con radioterapia, a fin de contribuir al conocimiento de esta eventualidad en el medio neuroquirúrgico.

Resultados. Los pacientes fueron dos niñas y un niño entre 2,5 y 7 años de edad (media 5,2 años). El intervalo medio entre la radioterapia y la aparición del cavernoma fue de 5,3 años (extremos 5 y 6 años). Las lesiones fueron encontradas en los estudios de neuroimagen que se realizan habitualmente a estos pacientes para seguimiento de sus tumores originarios. Durante el período de observación, ningún paciente presentó síntomas o signos relacionados con el cavernoma. No obstante, los tres niños requerirán un seguimiento clínico y de neuroimagen para vigilar la evolución clínica de estas lesiones descubiertas accidentalmente.

Conclusiones. La presencia de cavernomas intracraneales puede detectarse años después del tratamiento con radioterapia. Al contrario de casos previos publicados en los que fue frecuente su presentación con hemorragia, los cavernomas también pueden ser detectados de manera casual en los estudios de seguimiento que se realizan habitualmente a niños con tumores cerebrales tratados previamente con radioterapia. En este caso, parece aconsejable mantener una actitud conservadora, reservando la cirugía para las lesiones que crecen o sangran. 
PALABRAS CLAVE: Cavernoma. Incidentaloma. Cavernoma radioinducido. Meduloblastoma. Germinoma pineal. Complicaciones de la radioterapia.

\section{Introduction}

Cranial irradiation is widely used for treating brain tumors. This treatment often results in longer survival of patients, however late toxic effects such as radionecrosis, arteriopathy and second malignant neoplasms can occur in the brain ${ }^{1,12,16}$. Cavernomas are supposed to be vascular lesions of congenital origi $^{3,9}$. The incidence for sporadic cavernomas has been reported to be as high as $0.5 \%$ of the population ${ }^{3,9}$. In 1994 , Ciricillo et al. first suggested that cavernomas could be induced by irradiation ${ }^{5}$. Since then, some reports have attributed the formation of cavernomas to the treatment with radiotherapy ${ }^{1,2,4,6-11,13,14}$. In several instances, cavernomas manifested with spontaneous cerebral hemorrhage ${ }^{2}$ while, in others, the lesions were discovered during the evaluation of new symptoms unrelated to the initial brain tumor ${ }^{4,6,10,11,13}$. There are two possibilities to explain the formation of such lesions: they may be pre-existent to the brain tumor and radiotherapy or they may be caused by irradiation. At present, there is growing evidence that favors the second hypothesis.

The finding of cavernomas in three of our patients, during the follow-up of their brain tumors, has prompted us to report our experience on this occurrence. Our aim is to advertise, in the neurosurgical community, on the possibility of cavernoma induction following radiation therapy.

\section{Summary of patients}

We reviewed the medical records pertaining to three children, initially treated with surgery and radiotherapy for brain tumors, which were found to harbor a cavernoma during the routine surveillance performed for the followup of their previous conditions. At the time of their first hospital admission, the patients, two girls and a boy, were aged from 2.5 to 7 years. The girls were submitted to ventriculoperitoneal shunting and excision of cerebellar medulloblastoma. Subsequently, they were given radiotherapy that comprised the tumoral bed and the whole craniospinal axis, followed by a boost on the tumor site. One of these two girls also received chemotherapy. The third patient, a 7-year-old boy was managed with third ventriculostomy, local irradiation and chemotherapy for a pineal-region germinoma. The three patients were regularly followed-up at the outpatient clinic where neuroimaging studies were performed as part of the routine surveillance of their brain tumors. After a variable period, ranging from 5 to 6 years after radiation-therapy, a single cavernoma was found at their computerized tomography (CT) scan or magnetic resonance imaging (MRI) (Fig. 1-3). Cavernomas

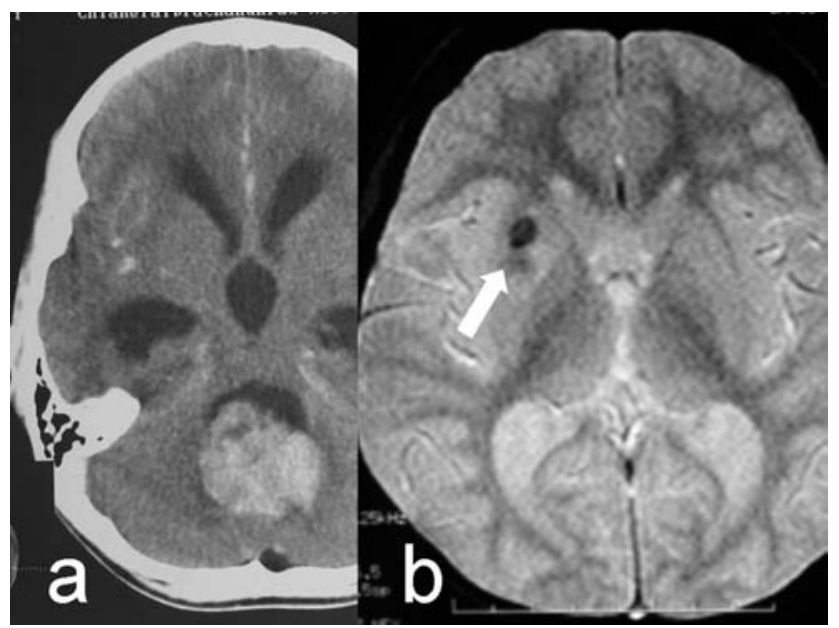

Fig. 1. (a) CT scan of Patient 1 showing a medulloblastoma. (b) MRI of the same patient depicting a radio-induced cavernoma on the right putamen (arrow)

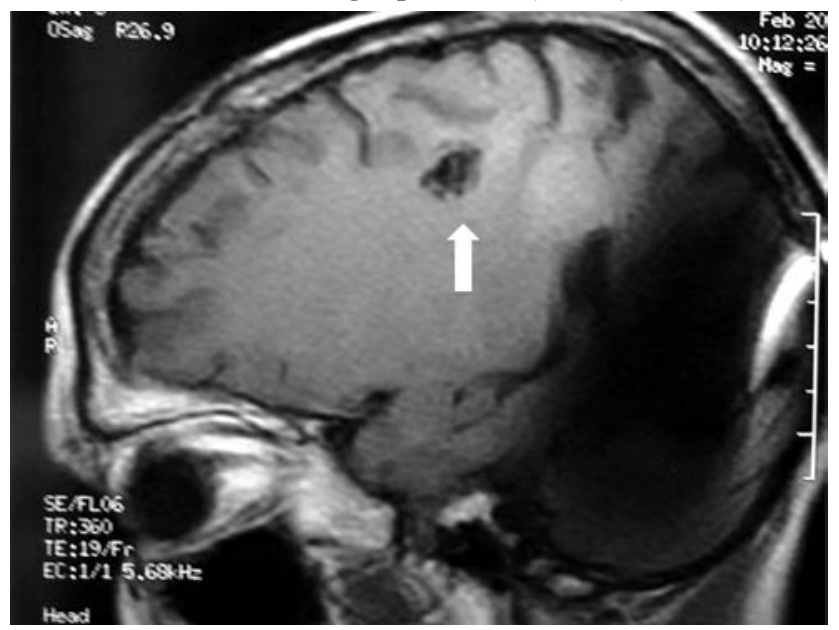

Fig. 2. MRI performed in Patient 2 showing a deep-seated cavernoma

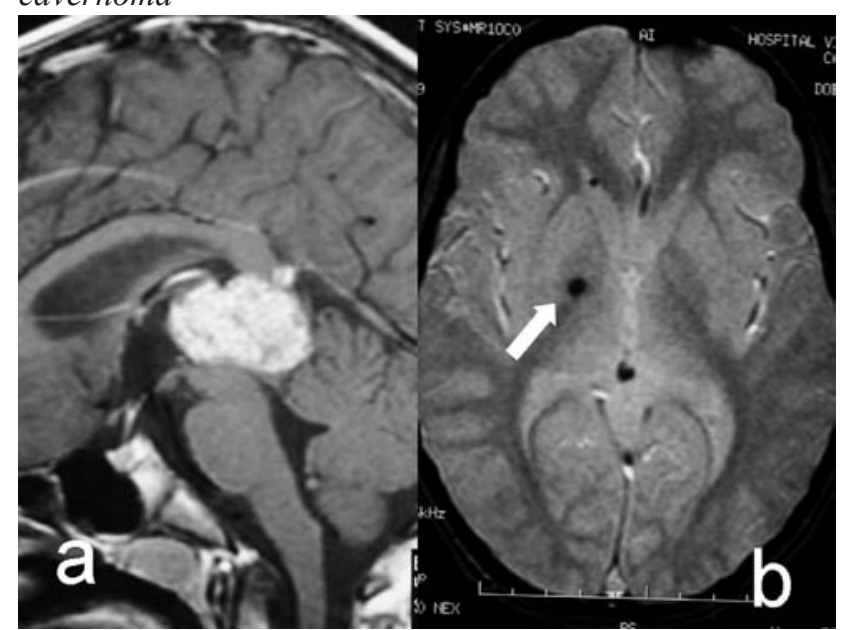

Fig. 3. (a) MRI of Patient 3 demonstrating a germinoma at the pineal region. (b) MRI of the same boy illustrating a radiation-induced cavernoma close to the right internal capsule. 
Table

Summary of three patients with post-radiation cavernomas

\begin{tabular}{|c|c|l|c|c|c|c|}
\hline No & $\begin{array}{c}\text { Sex \& age at } \\
\text { diagnosis }\end{array}$ & Initial disease & $\begin{array}{c}\text { RDT dose \& } \\
\text { type }\end{array}$ & Chemo-therapy & $\begin{array}{c}\text { Site of } \\
\text { cavernoma }\end{array}$ & $\begin{array}{c}\text { Latency of } \\
\text { cavernoma }\end{array}$ \\
\hline 1 & F, 2.5 yrs & Medulloblastoma & 40.6 Gy WCSA & Yes & Right putamen & 6 yrs \\
\hline 2 & F, 6 yrs & Medulloblastoma & 54 Gy WCSA & No & $\begin{array}{c}\text { Right centrum } \\
\text { semiovale }\end{array}$ & 5 yrs \\
\hline 3 & M, 7 yrs & Pineal germinoma & 40 Gy focal & Yes & $\begin{array}{l}\text { Right internal } \\
\text { capsule }\end{array}$ & 5 yrs \\
\hline
\end{tabular}

$\mathrm{F}=$ female, $\mathrm{M}=$ male, $\mathrm{RDT}=$ radiotherapy $, \mathrm{Gy}=\mathrm{Gray}, \mathrm{WCSA}=$ whole craniospinal axis,

in these children were surrounded by a faint rim of hemosiderin but there were neither clinical manifestations of their existence nor evidence of growth after a mean follow-up of 3.3 years (range 0.5 to 9 years) after diagnosis. The three lesions were deeply situated: one in the putamen, another in the internal capsule, and the third one in the centrum semiovale (Fig. 1-3). Clinical details of the patients are summarized in the Table. The estimated incidence of postirradiation cavernomas in our series was of $4.76 \%$ ( 3 of 63 children treated with radiotherapy for brain tumors).

\section{Discussion}

\section{Formation of cavernomas after radiotherapy}

Cavernomas, also known as cavernous hemangiomas, are CNS vascular lesions composed of thin-walled and dilated capillaries without intervening brain tissue ${ }^{3,9}$. The biological behavior of these lesions is incompletely understood. Cavernomas are believed to arise during early embryogenesis and to expand under malformative and vascular stimuli ${ }^{15}$. Several authors have addressed the issue of cavernoma development and expansion. De novo formation of cavernomas or radiation-induced cavernous angiomas has been reported in cases of both sporadic and familial lesions ${ }^{3,13}$. There are questions regarding if these lesions are developmental or acquired in nature and whether they carry a proliferating and/or neoangiogenic capacity $^{15}$. The potential of cerebrovascular malformations and cavernomas for endothelial proliferation, neoangiogenesis and generation of new lesions has been investigated by Sure et al. using immunohistochemical methods ${ }^{15}$.

Cranial irradiation may produce, at an early stage, vasogenic edema due to increased vascular permeability and vasodilatation. Delayed effects of radiotherapy on the
CNS include radionecrosis, gliosis, cerebral atrophy and radiation-induced tumors ${ }^{1,12,16}$. Late effects of irradiation on the brain vessels may produce hyalinization and fibrinoid necrosis of the vascular lining, vessel occlusion and infarction, and proliferative vasculopathies in the form of capillary telangiectasia and cavernous angiomas ${ }^{9}$.

There are two main theories to explain the appearance of cavernomas in patients treated with radiotherapy. The first supports the view that cavernous angiomas are preexistent lesions and that they are found simply after the treatment of the brain tumor. The second hypothesis sustains that cavernomas result from a proliferative vasculopathy that is started by radiation injury to the cerebral vessels ${ }^{9}$.

Poussaint et al. described 20 children with diverse CNS neoplasms including acute lymphoblastic leukemia and diverse cerebral tumors treated with radiotherapy that developed hemorrhagic vasculopathy and cerebral hemorrhage ${ }^{14}$. They discussed the pathophysiology of radiation injury. Ionizing radiation results in damage to the endothelial walls and produces focal alterations in the fibrinolytic enzyme system that leads to occlusion, thrombosis and ischemia with infarction ${ }^{8,14}$. They attribute the development of hemorrhages to disruption and alteration of capillary integrity by irradiation and also to lesions remarkably similar to cavernous angiomas ${ }^{8,14}$. Additional reports support the role of radiation injury in the development of de novo cavernomas $^{2,4-11,13}$.

On considering the risk factors involved in the development of radiation induced cavernomas and, in a similar way to those reported in the formation of second malignant neoplasms, two group of risk factors have to be taken into account: (a) therapy related factors, such as radiation therapy, dose, associated use of chemotherapy etc., and (b) factors inherent to the patients, such as age, immune status, genetic factors etc ${ }^{1,16}$. Nimjee et al. ${ }^{13}$ have recently 
reviewed the literature on de novo formation of cavernous angiomas of the CNS after radiotherapy. They collected 76 patients, with a mean age of 11.7 years and a male preponderance $^{13}$. Mean radiation dose was of 60.45 Gy and the latency period until the detection of cavernoma averaged 8.9 years. In most instances, the lesions were discovered incidentally ${ }^{13}$. The most frequent manifestation in the group of symptomatic patients was with seizures, while fifty percent of the patients had evidence of hemorrhage, which required surgery in roughly half of the cases ${ }^{13}$. The vast majority of patients belonged to the pediatric age group, being radiation-induced cavernomas exceptional in adults ${ }^{13}$. The commonest primitive neoplasm in this work was medulloblastoma ${ }^{13}$. The incidence of radiation-induced cavernomas in our experience was of 3 out of $63(4.76 \%)$ children irradiated for brain tumors, which is in agreement with the incidence reported by others ${ }^{4,6}$ that ranged between $2.15 \%$ and $3.4 \%$. A higher incidence (31\%) of cavernomas after cranial irradiation has been reported in children treated of medulloblastoma ${ }^{11}$.

\section{Diagnosis}

Children with brain tumors are often treated with both radiotherapy and chemotherapy and they may experience intracranial hemorrhage. Intracranial bleeding in these cases may also be due to thrombocytopenia from myelosuppression and cerebral or dural venous thrombosis with hemorrhagic infarction ${ }^{14}$. Another source of intracranial bleeding that must be considered in these patients is tumor recurrence and second tumors ${ }^{14}$. The neuroimaging diagnosis of cavernoma is readily achieved with MRI or CT. MRI usually shows a nidus with no surrounding cerebral edema, the core of the lesion shows an heterogeneous signal intensity with a dark rim of hemosiderin ("pop-corn" appearance $)^{9}$. Duhem et al. suggest that MRI should include a gradient echo sequence especially for detecting the smallest lesions, with other MRI sequences some cavernomas may remain undetected ${ }^{6}$. Vazquez et al. recommend performing MRI instead of CT scans in the follow-up of children with brain tumors to avoid the cumulative risks of irradiation and the possible induction of second neoplasms ${ }^{16}$. This is also applicable for the follow-up of children with radiationinduced cavernomas discovered incidentally.

\section{Treatment}

In Nimjee et al.'s review, 49 of 76 instances of radiation-related cavernomas had bled, being the hemorrhage related to the cavernoma in 37 cases $(76 \%)$ while in 12 $(24 \%)$ it was not ${ }^{13}$. Excision of cavernoma was undertaken in 20 patients $(54 \%)$ with hemorrhage ${ }^{13}$. Four additional patients with symptomatic lesions but who had not bled also underwent surgery. Briefly, in these authors' review, 27 of $76(38 \%)$ patients with post-radiation cavernomas underwent surgical excision while 44 (62\%) were followed conservatively ${ }^{13}$. In summary, incidentally discovered lesions must be followed conservatively, while surgery should be reserved for only those lesions that expand or bleed.

\section{Conclusions}

In the light of present knowledge, cavernous angiomas should be added to the list of late toxic effects of radiotherapy. It can be anticipated that the number of children with radiation-induced cavernomas will increase, as the survival of children with brain tumors treated with the newest therapies is growing. MRI seems to be the preferred method of neuroimaging for the follow-up of children with cerebral neoplasms for obvious reasons. Surgical indications should take into account clinical presentation (incidental or symptomatic), number, and localization of lesions as in cases of sporadic cavernomas. Long-life observation of patients with asymptomatic radiation-induced cavernomas seems to be advisable.

\section{References}

1. Amirjamshidi, A., Abbassioun, K.: Radiation-induced tumors of the CNS occurring in child and adolescence. Four unusual lesions and a review of the literature. Child's Nerv Syst 2000; 16: 390-397.

2. Baumgartner, J.E., Alter, J.L., Ha, C.S., et al.: Pathologically proven cavernous angiomas of the brain following radiation therapy for pediatric brain tumors. Pediatr Neurosurg 2003; 39: 201-207.

3. Bertalanffy, H., Benes, L., Miyazawa, T., Alberti, O., Siegel, A.M., Sure, U.: Cerebral cavernomas in the adult. Review of the literature and analysis of 72 surgically treated patients. Neurosurg Rev 2002; 25: 1-53.

4. Burn, S., Gunny, R., Phipps, K., Gaze, M., Hayward, R.: Incidence of cavernoma development in children after radiotherapy for brain tumors. J Neurosurg (5 Suppl Pediatrics) 2007; 106: 379-383.

5. Ciricillo, S.F., Cogen, P.H., Edwards, M.S.: Pediatric cryptic vascular malformations: presentation, diagnosis and management. Pediatr Neurosurg 1994; 20: 137-147.

6. Duhem, R., Vinchon, M., Leblond, P., Soto-Ares, G., Dhellemes, P.: Cavernous malformations after cerebral irradiation during childhood: report of nine cases. Child's Nerv Syst 2005; 21: 922-925.

7. Heckl, S., Aschoff, A,, Kunze, S.: Radiation-induced cavernous hemangiomas of the brain: a late effect predominantly in children. Cancer 2002; 94: 3285-3291.

8. Humpl, T., Bruhl, K,, Bohl, J., Schwarz, M., Stoeter, 
P., Gutjahr, P.: Cerebral hemorrhage in long-term survivors of childhood acute lymphoblastic leukaemia. Eur J Pediatr 1997; 156: 367-370.

9. Jain, R., Robertson, P.I., Gandhi, D., Gujar, S.K., Muraszko, K.M., Geharski, S.: Radiation-induced cavernomas of the brain. Am J Neuroradiol 2005; 26: 1158-1162.

10. Larson, J.J., Ball, W.S., Bove, K.E., Crone, K.R., Tew, J.M. Jr.: Formation of intracerebral cavernous malformations after radiation treatment for central nervous system neoplasia in children. J Neurosurg 1998; 88: 51-56.

11. Lew, S.M., Morgan, J.N., Psaty, E., Lefton, D., Allen, J.C., Abbott, R.: Cumulative incidence of radiation-induced cavernomas in long-term survivors of medulloblastoma. J Neurosurg (2 Suppl Pediatrics) 2006; 104: 103-107.

12. Martínez-Lage, J.F., Ros de San Pedro, J., Martínez Pérez, M., Poza, M.: Meningiomas after radiation-therapy for benign astrocytomas. Neurocirugía 2005; 16: 266-270.

13. Ninje, S.M., Powers, C.J., Bulsara, K.R.: Review of the literature on de novo formation of cavernous malformations of the central nervous system after radiation therapy. Neurosurg Focus 2006; 21: E4: 1-5.
2008; 19: 50-54

14. Poussaint, T.Y., Siffert, J., Barnes, P.D., et al.: Hemorrhagic vasculopathy after treatment of central nervous system neoplasia in childhood: diagnosis and follow-up. Am J Neuroradiol1995; 16: 693-699.

15. Sure, U., Butz, N., Schle.gel, J., et al.: Endothelial proliferation, neoangiogenesis, and potential de novo generation of cerebrovascular malformations. J Neurosurg 2001; 94: $972-$ 977.

16. Vazquez, E., Castellote, A., Piqueras, J., et al.: Second malignancies in pediatric patients: imaging findings and differential diagnosis. Radiographics 2003; 23: 1155-1172.

Martínez-Lage, J.F.; de la Fuente, I.; Ros de San Pedro, J.; Fuster, J.L.; Pérez-Espejo, M.A.; Herrero, M.T.: Cavernomas in children with brain tumors: a late complication of radiotherapy. Neurocirugía 2008; 19: 5054.

Correspondencia postal: Dr. Juan F. Martínez-Lage. Servicio Regional de Neurocirugía. Hospital Universitario "Virgen de la Arrixaca". E-30120, El Palmar, Murcia, Spain. 